\title{
Equine Anti-thymocyte Globulin/Prednisone/Tacrolimus Regimen
}

National Cancer Institute

\section{Source}

National Cancer Institute. Equine Anti-thymocyte Globulin/Prednisone/Tacrolimus

Regimen. NCl Thesaurus. Code C160562.

A chemoimmunotherapy regimen consisting of equine anti-thymocyte globulin, prednisone and tacrolimus that can be used in the treatment of myelodysplastic syndrome (MDS) and the prevention and treatment of graft rejection. 